\title{
Bacterial consortium and axenic cultures isolated from activated sewage sludge for biodegradation of imidazolium-based ionic liquid
}

\author{
M. Markiewicz $\cdot$ J. Henke $\cdot$ A. Brillowska-Dąbrowska • \\ S. Stolte $\cdot$ J. Luczak $\cdot$ C. Jungnickel
}

Received: 16 May 2012/Revised: 7 June 2013/Accepted: 9 October 2013/Published online: 5 November 2013

(C) The Author(s) 2013. This article is published with open access at Springerlink.com

\begin{abstract}
Extensive research and increasing number of potential industrial applications made ionic liquids (ILs) important materials in design of new, cleaner technologies. Together with the technological applicability, the environmental fate of these chemicals is considered and significant efforts are being made in designing strategies to mitigate their potential negative impacts. Many ILs are proven to be poorly biodegradable and relatively toxic. Bioaugmentation is known as one of the ways of enhancing the microbial capacity to degrade xenobiotics by addition of specialized strains. The aim of current work was to select microbial species that could be used for bioaugmentation in order to enhance biodegradation of ILs in the environment. We subjected activated sewage sludge to the selective pressure of 1-methyl-3-octylimidazolium chloride $([\mathrm{OMIM}][\mathrm{Cl}])$ and isolated nine strains of bacteria which were able to prevail in these conditions. Subsequently, we utilized axenic cultures (pure cultures) of these bacteria as well as mixed consortium to degrade this IL. In addition, we performed growth inhibition tests and found that bacteria were able to grow in $2 \mathrm{mM}$, but not in $20 \mathrm{mM}$
\end{abstract}

M. Markiewicz ( $₫)$ · J. Henke · J. Łuczak · C. Jungnickel Department of Chemical Technology, Chemical Faculty, Gdańsk University of Technology, ul. Narutowicza 11/12,

80-233 Gdańsk, Poland

e-mail: martam@chem.pg.gda.pl

A. Brillowska-Dąbrowska

Department of Microbiology, Chemical Faculty, Gdańsk

University of Technology, ul. Narutowicza 11/12,

80-233 Gdańsk, Poland

S. Stolte

Center for Environmental Research and Sustainable Technology, University of Bremen, UFT Leobener Strasse, 28359 Bremen, Germany solutions of [OMIM][Cl]. The biodegradation conducted by the isolated consortium was higher than conducted by the activated sewage sludge when normalized by the cell density, which indicates that the isolated strains seem specifically suited to degrade the IL.

Keywords Biodegradation - Growth inhibition - Ionic liquid · Axenic culture - Bioaugmentation - Ecotoxicity · Hormesis

\section{Introduction}

Ionic liquids (ILs) are chemicals usually composed of large asymmetric, organic cation and organic or inorganic anion. Physical and chemical properties of this group of compounds can vary significantly what allows them to be designed for a particular purpose (Krossing et al. 2006). The last decade has shown a growing interest in the application of ILs in gas storage and separation, catalysis, electrodeposition of metals, waste and biomass reprocessing, energy production, etc. (Kragl et al. 2002; Jiang et al. 2006; Plechkova and Seddon 2008). When applied in such industrial processes, ILs will inevitably emerge in wastewaters and might end up in natural soils or water bodies by breaking through treatment systems or due to the accidental release during transport and storage. Although, the low volatility of ILs can be an advantage in reducing air emissions and thereby decreasing the risk of human exposure, the relatively high toxicity and resistance to biotic and abiotic degradation that could be observed for some of the ILs structures is a concern (Romero et al. 2008).

Biodegradation of substituted imidazolium cation was examined in detail by a number of research groups 
(Gathergood et al. 2006; Romero et al. 2008; Stolte et al. 2008; Markiewicz et al. 2009; Abrusci et al. 2010; Coleman and Gathergood 2010). Stolte et al. conducted a comprehensive study of biodegradation of 1-methyl-3-alkylimidazolium chlorides. No primary biodegradation was observed for methyl- to butyl-substituted compounds, even those containing oxygen atoms introduced into the alkyl chain (as ethers or terminal hydroxyl groups) which are known to increase biodegradability. Better biodegradability was observed for higher homologs with 1-methyl-3-octylimidazolium chloride reaching $100 \%$ biodegradation after 24 day of the test (Stolte et al. 2008). In most IL biodegradation tests, activated sewage sludge is used as an inoculum as it is composed of multiple species with a wide taxonomic diversity and is therefore more likely to contain specie or species capable of degrading ILs (Gathergood et al. 2006; Romero et al. 2008; Stolte et al. 2008; Markiewicz et al. 2009). In the previously mentioned work, Stolte et al. examined the ability of commercially available freeze-dried bacteria mixture to biodegrade ILs and concluded that it was unable to degrade any of tested compounds. Modelli et al. used inoculum derived from top soil for biodegradation of ILs under ASTM D 5988-96 test conditions and found it capable of degrading 1-butyl-3-methylimidazolium chloride (Modelli et al. 2008). Abrusci et al. used a strain of Sphingomonas paucimobilis isolated from cinematographic film for biodegradation of some common ILs and found it predisposed to degrade many tested compounds including those previously reported to be non-biodegradable. However, a somehow surprising trend was observed by Abrusci et al. for imidazolium chlorides showing highest biodegradation for ethyl- and lowest for octyl- and decyl-substituted compounds (Abrusci et al. 2010).

Some bacterial species are capable of tolerating or even growing in the presence of xenobiotics (Isken and deBont 1998; Takenaka et al. 2007). In pursuit of understanding the mechanisms of bacterial resistance and adaptation to xenobiotics, it was revealed that resistance is either a natural property of a species or is acquired by genetic changes (Weber and deBont 1996; Pham et al. 2009). The ability to degrade xenobiotics is not simply a function of the amount of biomass of inoculum, although very often a correlation between the two exists. Activated sewage sludge community is often used in biodegradation tests as it is expected that degraders of xenobiotics will be encountered among the multitude of species. Assuring this by adding specialized species is known as (bio)augmentation and was previously suggested as a promising strategy to enhance the degradative capacity of soils and sewage sludge (Limbergen et al. 1998; Pieper and Reineke 2000). For this reason, an attempt to identify the exact microbial strains which might be partaking in the process of biological degradation of ILs was undertaken here in order to uncover specie or species especially predisposed to degrade ILs. Would the attempt be successful, it might present a very useful tool in enhancing biodegradation of ILs by augmenting indigenous microbial communities. As activated sewage sludge was clearly proven to be the most potent in biodegrading ILs, it was chosen as a starting point. For the current test, 1-methyl-3-octylimidazolium chloride was selected since it was previously shown to be biodegradable in activated sewage sludge, and therefore, it will allow for comparative statements to be drawn. A nearly 30-fold increase in maximum biodegradable concentration and growing rates of degradation resulting from pre-exposition of activated sewage sludge community to this IL were reported before. Moreover, a break-down of the imidazolium ring was observed (Markiewicz et al. 2011). In the course of the current work, nine strains of bacteria from adapted activated sewage sludge were isolated, and the influence of 1-methyl-3-octylimidazolium chloride on their growth was tested. The performance of consortium of all isolated strains and of each strain individually was verified in 'Manometric respirometry' biodegradation test using the same IL. Results of these tests are presented hereby.

\section{Materials and methods}

\section{Chemicals}

The investigated ionic liquid 1-methyl-3-octylimidazolium chloride was purchased from Merck KGaA (Germany) with a purity of $\geq 98 \%$. The molecular weight, chemical formula and molecular structure are shown in Table 1.

\section{Selection of resistant isolates}

The experiments were carried out at the Department of Chemical Technology, Gdańsk University of Technology and at the Center for Environmental Research and Sustainable Technology, University of Bremen. The sewage was sampled in June 2009, and the measurements were carried out in the subsequent 10 months. Activated sewage sludge was obtained from aeration tank of municipal wastewater treatment plant (WWTP) 'Wschód' in Gdańsk, Poland, and used for biodegradation experiment during which it was subjected to selective pressure of [OMIM][Cl] as described in Markiewicz et al. (2009). Subsequently, microbial strains were isolated and identified as described below.

\section{Bacterial species identification}

Activated sewage sludge, obtained from the last phase of biodegradation test, was diluted with saline $(0.85 \% \mathrm{NaCl})$ 
Table 1 Ionic liquid

investigated

\begin{tabular}{llll}
\hline Name & Chemical formula & Molecular structure & $\begin{array}{l}\text { Molecular mass } \\
(\mathrm{g} / \mathrm{mol})\end{array}$ \\
\hline $\begin{array}{l}\text { 1-Methyl-3-octylimidazolium } \\
\text { chloride }\end{array}$ & $\mathrm{C}_{12} \mathrm{H}_{23} \mathrm{ClN}_{2}$ &
\end{tabular}

solution. Samples diluted from 1 to 5 times were then inoculated into Petri dishes containing Luria Agar (LA) using spread-plate method and incubated in $16{ }^{\circ} \mathrm{C}$ for $48 \mathrm{~h}$. To obtain pure cultures, single colonies were chosen and inoculated to Petri dishes with LA agar, using streak plate method and incubated. Single colonies were inoculated to test tubes with $2 \mathrm{~mL}$ of Luria Broth (LB) and cultivated. After $48 \mathrm{~h}, 100 \mu \mathrm{L}$ of each liquid culture was inoculated into Petri dishes containing LA agar by spread-plate method and cultured for $48 \mathrm{~h}$ at $16{ }^{\circ} \mathrm{C}$. Bacterial isolates from activated sewage sludge were subjected to Gram staining and observed under optical microscope.

Molecular identification of bacterial isolates

DNA was purified by mean of Genomic Mini Kit (A\&A Biotechnology, Poland). PCR with universal 16S rDNA primers: 16S-for 5'GGACTACCAGGGTATCTAATC $3^{\prime}$ and 16S-rev $5^{\prime}$ GATCCTGGCTCAGGATGAAC $3^{\prime}$ and REDTaq $^{\circledR}$ ReadyMix PCR Reaction Mix (Sigma-Aldrich ${ }^{\circledR}$ ) were performed with isolated DNA of nine bacterial strains in a volume of $20 \mu \mathrm{L}$. The time-temperature profile for PCR was 35 cycles of $30 \mathrm{~s}$ at $94{ }^{\circ} \mathrm{C}, 30 \mathrm{~s}$ at $55^{\circ} \mathrm{C}$ and $45 \mathrm{~s}$ at $72{ }^{\circ} \mathrm{C}$, preceded by initial denaturation for $10 \mathrm{~min}$ at $95^{\circ} \mathrm{C}$. The presence of specific PCR products of approximately $800 \mathrm{bp}$ was examined using electrophoresis on a $1 \%$ agarose gel and staining with ethidium bromide.

The PCR products were purified with High Pure PCR Product Purification Kit (Roche) and sequenced (Genomed, Poland). The identification of isolates was performed by comparison of obtained sequences against the sequences from GenBank (http://blast.ncbi.nlm.nih.gov)

Growth inhibition test

Fresh bacterial cultures of the nine isolates were grown in LB broth (cell density $4 \cdot 10^{8}$ cells/L). IL ([OMIM][Cl]) was used in four concentrations: $0.2 ; 2 ; 20$ and $200 \mathrm{mM}$. Positive control samples, containing LB, inoculum and sodium glutamate with the same carbon content as respective samples with IL_-one for each microorganism-were prepared. Additionally, the sample with LB and IL only served as a negative control. All prepared samples were then incubated in $16^{\circ} \mathrm{C}$ for $48 \mathrm{~h}$. After incubation, in order to determine the growth rate in each sample, $200 \mu \mathrm{L}$ of each solution was transferred to the disposable microplate, and the quantity of bacterial cells was determined spectrophotometrically using a multilabel plate reader Wallac 1420 VICTOR $^{3}-\mathrm{V}(\lambda=595 \mathrm{~nm}$ wavelength $)$.

Biodegradation tests

Ready biodegradability tests of 1-methyl-3-octylimidazolium chloride in concentration of $0.2 \mathrm{mM}$ using $1 \mathrm{~mL}$ of axenic cultures (resulting in cell density of $8 \cdot 10^{4}$ cells/ $\mathrm{L}$ in each culture) of nine isolates were performed according to OECD $301 \mathrm{~F}$ 'Manometric respirometry' procedure (OECD 1992). In this test, biodegradation is measured as a decrease in pressure in gas-tight test vessel caused by depletion of oxygen used for aerobic degradation of IL reduced by the blank sample value (sample showing only endogenous respiration of bacteria, without addition of test compound) with respect to the theoretical amount of oxygen necessary to completely oxidize the compound tested. Since almost no biodegradation was observed, the same test was repeated for a consortium composed of all nine isolates (cell density $8 \cdot 10^{5}$ cells/L of all strains in total) in a concentration of IL previously reported to be low enough for biodegradation with activated sewage sludge to occur (0.25 mM) (Stolte et al. 2008). Samples containing activated sewage sludge (cell density $10 \cdot 10^{7}$ cells/L) derived from 'Wschód' in Gdańsk, were also employed in the test for the sake of comparison.

\section{Results and discussion}

Isolation and identification of sewage sludge bacteria

Nine different isolates of microorganisms were cultivated from original biodegradation test utilizing activated sewage sludge. After DNA isolation, followed by $16 \mathrm{~S}$ rDNA PCR and product purification, the DNA sequencing was conducted. The obtained sequences were compared with GenBank data (NCBI 2011), and microbial species were identified.

Table 2 summarizes the results of identification and Gram staining. Figure 1 presents the phylogenetic tree of identified species. The sequence alignment and bootstrap values were calculated using CLUSTALW2.012. 
Table 2 Microbial isolates identified by sequencing of 16S rDNA sequences comparison with GenBank data (NCBI 2011)

\begin{tabular}{llc}
\hline No. & Organism & Gram \\
\hline 1 & Flavobacterium sp. WB3.2-27 & - \\
2 & Shewanella putrefaciens CN-32 & - \\
3 & Moraxellaceae Bacterium MAG & - \\
4 & Flavobacterium sp. FB7 & - \\
5 & Microbacterium keratanolyticum AO17b & + \\
6 & Flavobacterium sp. WB 4.4-116 & - \\
7 & Arthrobacter sp. SPC 26 & + \\
8 & Rhodococcus sp. PN8 & + \\
9 & Arthrobacter protophormiae strain DSM 20168 & + \\
\hline
\end{tabular}

Growth inhibition

The inhibition of growth of nine isolated bacterial strains by 1-methyl-3-octylimidazolium chloride [OMIM][Cl] in four concentrations covering four orders of magnitude was examined. Therefore, the strains were incubated in the presence of IL for $48 \mathrm{~h}$, and afterward, the cell density was determined spectrophotometrically. The results were expressed as a percent of growth in relation to a positive control with sodium glutamate (Fig. 2).

Concentration-dependent decrease in growth was found. In $0.2 \mathrm{mM}$ [OMIM][Cl], most of strains showed a similar decrease in growth (10-20\%) except strains 4 and 5 where growth reached approximately 150 and $120 \%$ of positive control, respectively. This might suggest that those two species are especially predisposed to utilizing [OMIM][Cl] as carbon source or, more probably, might have been a result of hormesis. It is believed that when exposed to low doses of toxin, organisms exhibit increased growth by investing larger amounts of energy in reproduction in order to assure survival (Calabrese 2005). It is possible that for Flavobacterium sp. FB5 and Microbacterium keratanolyticum, this concentration of IL triggered the hormetic effect.

Increasing IL concentration to $2 \mathrm{mM}$ caused $50-60 \%$ inhibition of growth for most of strains. Microbacterium keratanolyticum proved to be particularly sensitive (75\% inhibition) supporting hypothesis of hormesis. No
Fig. 1 Phylogenetic tree of identified species (visualized using iTOL Letunic and Bork 2007)

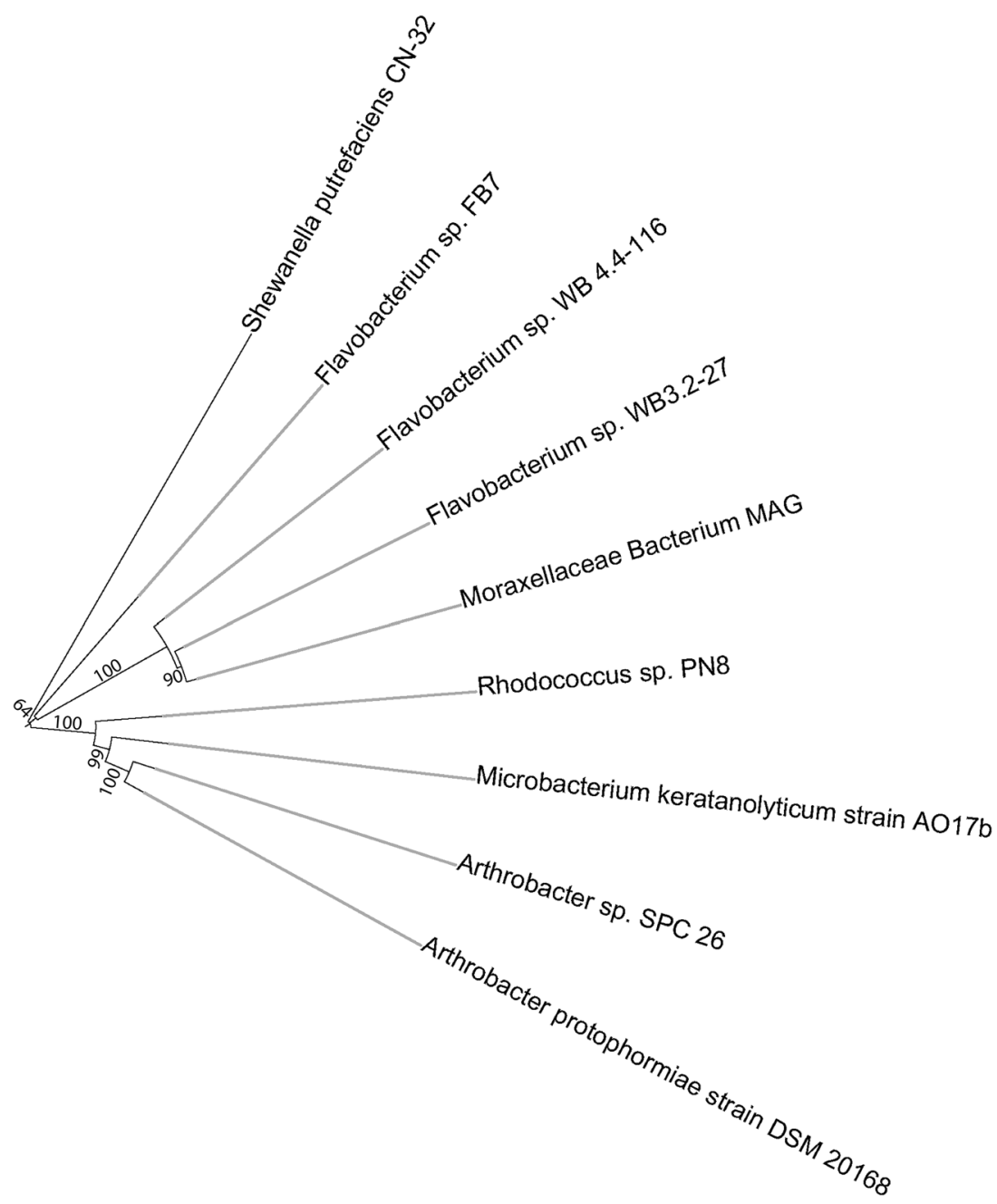




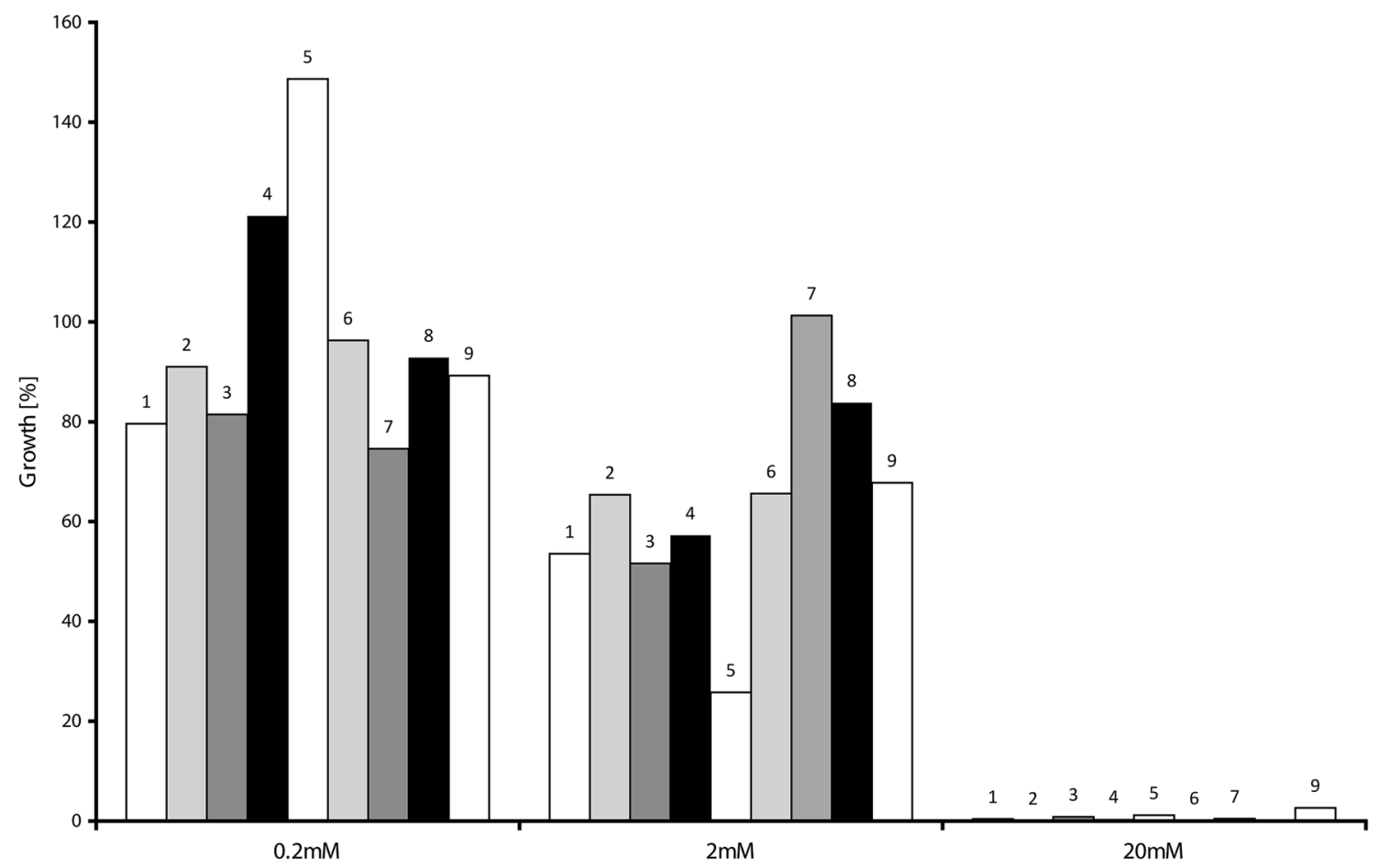

Fig. 2 Growth of the selected bacterial strains in solution containing various concentrations of [OMIM][Cl] is displayed as a percent of positive control. Strains were numbered in accordance to Table 2

inhibition of growth of Arthrobacter sp. SPC 26 and only minor inhibition of Rhodococcus sp. PN8 were found. Enhanced growth of Arthrobacter sp. as compared $2 \mathrm{mM}$ sample can again be explained by hormesis. Rhodococcus exhibited steady growth in both 0.2 and $2 \mathrm{mM}$ samples, making this strain the most tolerant for IL.

Most of isolated strains proved to be slightly more resistant to IL than previously reported by Łuczak et al. (2010), where at least $80 \%$ growth inhibition was observed in $4 \mathrm{mM}$ [OMIM][Cl] for Gram-negative Escherichia coli and in $2 \mathrm{mM}$ [OMIM][Cl] for three other Gram-positive bacterial strains. The growth observed for samples containing $20 \mathrm{mM}$ IL solution was almost negligible and completely inhibited in $200 \mathrm{mM}$ solutions (results not shown).

A variety of negative effects of chemicals on function of bacterial cells are known. For example, membrane permeabilization is caused by adsorption of molecules, resulting in leakage of cytoplasm and micromolecules or simply inability to maintain cell integrity. Other effects include the decrease in the cell energy status caused by passive flux of ions through the membrane, the disturbance of functions of other (not involved in energy transduction) proteins present in the membrane as well as the distortions in fluidity and the hydration of the membrane surface (Isken and deBont 1998). Bacterial cells might counteract these effects by adaptation at the level of cytoplasmic membrane, including changes in level of saturation of fatty acids which changes the fluidity of membrane in order to compensate the negative effect of chemicals (known as homeoviscosic adaptation Heipieper and deBont 1994); reduction in cell hydrophobicity by altering the content of lipopolysaccharide (LPS) and modification of porines which was proven to increase the solvent tolerance of microorganism; solvents degradation into lessor nontoxic substances and the solvent active excretion from the cell (Isken and deBont 1998). It would be expected that bacteria able to survive in unfavorable conditions created by the presence of ionic liquids would employ one of these mechanisms in order to survive, yet not necessarily will be able to break them down. The difference in cell wall construction of Gram-positive and Gram-negative bacteria might be responsible for their slightly different resistance toward chemicals. Even though Gram-negative cell wall is much thinner, it is covered with an additional lipid membrane acting as a barrier for many biocides, and thus, Gram-negative microorganisms show lower sensitivity to organic chemicals including surfactants (Blazevic 1976; Volkering et al. 1995). The same regularity, though only slightly pronounced, was observed by Łuczak et al. for ILs (Luczak et al. 2010). Nevertheless, no obvious differences in growth inhibition between Gram-positive and Gram-negative bacteria were observed within this work. 
Biodegradation tests

All isolated stains from previous experiment (Markiewicz et al. 2009) were tested in biodegradation tests according to OECD $301 \mathrm{~F}$ (Manometric respirometry) in order to determine the mineralization of [OMIM][Cl]. None of the isolates exhibited any significant levels of biodegradation of 1-methyl-3-octylimidazolium chloride when applied as an axenic culture. A maximum value of $8 \%$ was observed for Microbacterium keratanolyticum (results not shown) which was expected as this strain showed the highest growth rate in growth inhibition test in $0.2 \mathrm{mM}$ sample. It is probable that not an axenic culture but a consortium of two or more strains is necessary to conduct full biodegradation of IL. Numerous examples of such situations can be found in literature. Consortia of bacteria were found to degrade azo-dyes, crude oil hydrocarbons, atrazine, etc., more efficiently than individual strains (Zwieten and Kennedy 1995; Khehra et al. 2005; Adebusoye et al. 2007). There are a number of interactions within a consortium that lead to degradation of a xenobiotic and that cannot occur in axenic culture. These are unfortunately very difficult to uncover. It may be that the first step is conducted by one organism resulting in an intermediate that is then transformed further by another organism, and this cascade proceeds to full mineralization. At some point, more than one organism can be involved in the degradation of intermediates leading to different products and consequent ramification of the metabolic pathway. It is also possible that some members of the consortia do not take part in the degradation of the xenobiotic, but support the primary degraders providing them with essential nutrients, e.g., vitamins, amino acids or creating appropriate environmental conditions such as removing toxins and adjusting oxygen levels. It is therefore far more likely that enhanced degradation can be achieved by augmentation with a consortium rather that an axenic culture (Grady 1985; Schink 2002).

The results of the biodegradation test with the consortium formed by mixing all nine isolates are shown in Fig. 3a. Biodegradation of sodium glutamate was also conducted to examine the viability of the inoculum. Additionally, biodegradation of both [OMIM][Cl] and sodium glutamate conducted by activated sewage sludge is displayed for comparison

It is clear that both microbial communities were viable as sodium glutamate was completely degraded in both cases-degradation in activated sewage sludge was completed within 4 days and in the mixed strain consortium in 16 days. [OMIM] [Cl] was degraded by activated sewage sludge at almost $60 \%$ by the end of the test which corresponds theoretically to a degradation of the octyl side chain without degradation of the imidazolium ring. Nevertheless,
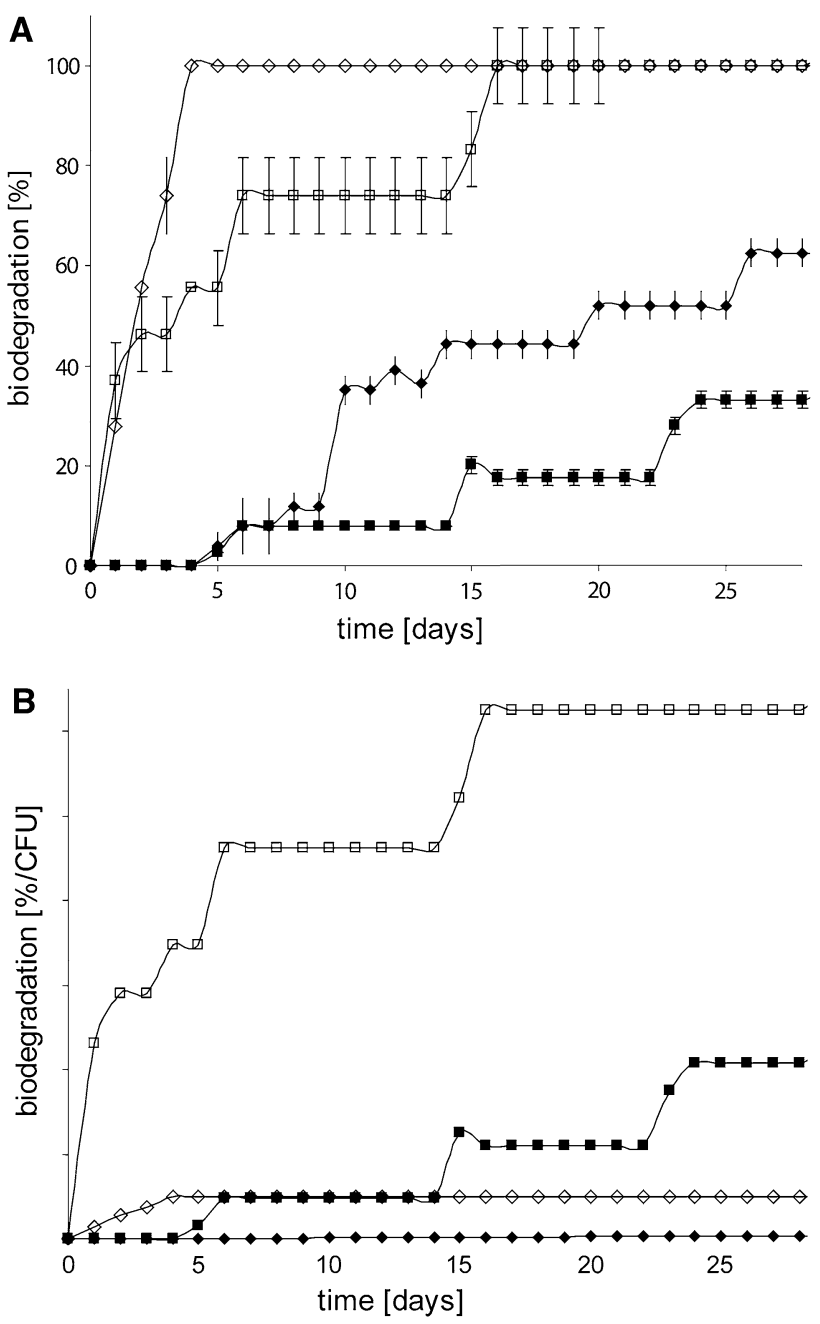

Fig. 3 Biodegradation (a) and biodegradation normalized for cell density (b) of [OMIM][Cl] (closed symbols) and sodium glutamate (open symbols) by activated sewage sludge (diamonds) and consortium of nine isolated strains (squares)

[OMIM] $[\mathrm{Cl}]$ could not be classified as readily biodegradable on the basis of this result. Biodegradation of $[\mathrm{OMIM}][\mathrm{Cl}]$ by the mixed strain consortium occurred slower and reached slightly above $30 \%$ on the twentyeighth day of the test, most probably this also involved the biodegradation of the side chain. The differences in the degradation rates are possibly due to the different cell densities in the consortium and activated sewage sludge as well as different microbial composition. The dry mass cannot be used as a direct comparison, as the dry mass of sewage is partially comprised of a mineral fraction, extracellular polymeric substance as well as other organisms like fungi and protozoa. Therefore, to obtain a comparison of the various cultures, the cell density was determined by counting the colony-forming units. When normalized for cell density (Fig. 3b), the rate of biodegradation is much higher in case of mixed strain consortium. 
This difference in rates is of course only an indicative result, since the cell density of sewage is several orders of magnitude higher (and therefore, the \% degradation/CFU will always be lower). However, it highlights the potential that such mixed strain consortia might have.

\section{Conclusion}

Docherty et al. previously reported on changes in microbial genetic patterns of organisms cultivated in media containing ILs, suggesting that enrichment of certain species occurred (Docherty et al. 2007). We decided to follow this lead and isolated bacterial strains from activated sewage sludge subjected to selective pressure of 1-methyl-3-octylimidazolium chloride.

Nine bacterial isolates were identified. Three of them belonged to Flavobacteriaceae family, two to family Micrococcaceae and the remaining strains to the families: Shewanellacae, Moraxellaceae, Microbacteriaceae, Nocardiaceae. All strains grew well in $0.2 \mathrm{mM}$ [OMIM][Cl] and were inhibited in $40 \%$ on average in $2 \mathrm{mM}$ solutions. Any higher concentrations inhibited growth almost completely.

Axenic cultures of single isolates were proven to be rather inefficient in degrading [OMIM] $[\mathrm{Cl}]$ and application of a consortium composed of all mixed strains resulted in $30 \%$ ultimate degradation. In the same conditions, activated sewage sludge organisms degraded almost $60 \%$ of the tested compound which corresponds to full degradation of alkyl substituents. The lower result obtained for the mixed strain consortium might have been a result of lower cell density in these samples. A higher degradation rate was observed in case of mixed strains when results were normalized for cell density in consortium. It is possible that not all of isolates involved in ILs metabolism were selected or that isolated microorganisms were a part of more complex consortium connected by symbiotic relations with other organisms and that, in their presence, even higher metabolic capacities could have been achieved.

We have recently shown that adapted microbial communities can degrade [OMIM] $[\mathrm{Cl}]$ faster and can withstand higher concentrations of that IL without an inhibitory effect compared with non-adapted communities (Markiewicz et al. 2011). Therefore, more research is needed in order to uncover species involved in [OMIM][Cl] degradation and to examine the feasibility of using adapted single strains or consortia in enhancing degradative abilities of indigenous microorganisms. Obtaining high cell density inocula of strains isolated here and comparing them with activated sludge of the same cell density would unequivocally confirm their better performance. Additionally, simulation tests in high biomass content systems (e.g., OECD tests
303 OECD 2001) in combination with augmentation of freshly sampled activated sludge with nine isolates could help to prove the technological viability of this approach.

Acknowledgments Financial support was provided by the Polish Ministry of Science and Higher Education Grant No.: N305 320636 in the years 2009-2011 and N305 327439 in years 2010-2011 and by the European Union within the European Social Fund in project "InnoDoktorant-Scholarships for PhD students, 2nd edition". Help of Ms. Iwona Henke in performing strain isolation is greatly acknowledged. We would like to thank Daniel Szopiński for the artwork. In addition, we would like to thank Aleksandra Markiewicz for her assistance with bioinformatics.

Open Access This article is distributed under the terms of the Creative Commons Attribution License which permits any use, distribution, and reproduction in any medium, provided the original author(s) and the source are credited.

\section{References}

Abrusci C, Palomar J, Pablos JL, Rodriguez F, Catalina F (2010) Efficient biodegradation of common ionic liquids by Sphingomonas paucimobilis bacterium. Green Chem 3:709-717

Adebusoye SA, Ilori MO, Amund OO, Teniola OD, Olatope SO (2007) Microbial degradation of petroleum hydrocarbons in a polluted tropical stream. World J Microbiol Biotechnol 23(8): $1149-1159$

Blazevic DJ (1976) Current taxonomy and identification of nonfermentative gram negative bacilli. Hum Pathol 7(3):265-275

Calabrese EJ (2005) Paradigm lost, paradigm found: the re-emergence of hormesis as a fundamental dose response model in the toxicological sciences. Environ Pollut 138:378-411

Coleman D, Gathergood N (2010) Biodegradation studies of ionic liquids. Chem Soc Rev 39:600-637

Docherty KM, Dixon JK, Jr CFK (2007) Biodegradability of imidazolium and pyridinium ionic liquids by an activated sludge microbial community. Biodegradation 18:481-493

Gathergood N, Scammells PJ, Garcia MT (2006) Biodegradable ionic liquids Part III: the first readily biodegradable ionic liquids. Green Chem 8:156-160

Grady LCPJ (1985) Biodegradation: its measurement and microbiological basis. Biotechnol Bioeng 27:660-674

Heipieper HJ, deBont JAM (1994) Adaptation of Pseudomonas putida S12 to ethanol and toluene at the level of fatty acid composition of membranes. Appl Environ Microbiol 60(12): $4440-4444$

Isken S, deBont JAM (1998) Bacteria tolerant to organic solvents. Extremophiles 2:229-238

Jiang T, Brym MJC, Dubé G, Lasia A, Brisard GM (2006) Electrodeposition of aluminium from ionic liquids: part IIstudies on the electrodeposition of aluminum from aluminum chloride (AICl3) - trimethylphenylammonium chloride (TMPAC) ionic liquids. Surf Coat Technol 201:10-18

Khehra MS, Saini HS, Sharma DK, Chadha BS, Chimni SS (2005) Comparative studies on potential of consortium and constituent pure bacterial isolates to decolorize azo dyes. Water Res 39(20):5135-5141

Kragl U, Eckstein M, Kaftzik N (2002) Enzyme catalysis in ionic liquids. Curr Opin Biotechnol 13:565-571

Krossing I, Slattery JM, Daguenet C, Dyson PJ, Oleinikova A, Weingaertner H (2006) Why are ionic liquids liquid? A simple 
explanation based on lattice and solvation energies. J Am Chem Soc 128:13427-13434

Letunic I, Bork P (2007) Interactive tree of life (iTOL): an online tool for phylogenetic tree display and annotation. Bioinformatics 23(1):127-128

Limbergen HV, Top EM, Verstraete W (1998) Bioaugmentation in activated sludge: current features and future perspectives. Appl Microbiol Biotechnol 50:16-23

Łuczak J, Jungnickel C, Łącka I, Stolte S, Hupka J (2010) Antimicrobial and surface activity of 1-alkyl-3-methylimidazolium derivatives. Green Chem 12:593-601

Markiewicz M, Jungnickel C, Markowska A, Szczepaniak U, Paszkiewicz M, Hupka J (2009) 1-Methyl-3-octylimidazolium chloride-sorption and primary biodegradation analysis in activated sewage sludge. Molecules 14:4396-4405

Markiewicz M, Stolte S, Lustig Z, Łuczak J, Skup M, Hupka J, Jungnickel C (2011) Influence of microbial adaption and supplementation of nutrients on the biodegradation of ionic liquids in sewage sludge treatment processes. J Hazard Mater 195(15):378-382

Modelli A, Sali A, Galletti P, Samori C (2008) Biodegradation of oxygenated and non-oxygenated imidazolium-based ionic liquids in soil. Chemosphere 73(8):1322-1327

NCBI (2011) GenBank. From http://www.ncbi.nlm.nih.gov/genbank/

OECD (1992) OECD guideline for testing of chemicals 301—ready biodegradability

OECD (2001) Simulation test-aerobic sewage treatment

Pham TPT, Cho C-W, Jeon C-O, Chung Y-J, Lee M-W, Yun Y-S (2009) Identification of metabolites involved in the biodegradation of ionic liquid 1-butyl-3-methylpyridinium bromide by activated sludge microorganisms. Environ Sci Technol 43:516-521
Pieper DH, Reineke W (2000) Engineering bacteria for bioremediation. Curr Opin Biotechnol 11:262-270

Plechkova NV, Seddon KR (2008) Applications of ionic liquids in the chemical industry. Chem Soc Rev 37:123-150

Romero A, Santos A, Tojo J, Rodriguez A (2008) Toxicity and biodegradability of imidazolium ionic liquids. J Hazard Mater 151:268-273

Schink B (2002) Synergistic interactions in the microbial world. Antonie Van Leeuwenhoek 81(1-4):257-261

Stolte S, Abdulkarim S, Arning J, Blomeyer-Nienstedt A-K, BottinWeber U, Matzke M, Ranke J, Jastorff B, Thöming J (2008) Primary biodegradation of ionic liquid cations, identification of degradation products of 1-methyl-3-octyl-imidazolium chloride and electrochemical waste water treatment of poorly biodegradable compounds. Green Chem 10:214-224

Takenaka S, Tonoki T, Taira K, Murakami S, Aoki K (2007) Adaptation of Pseudomonas sp. strain 7-6 to quaternary ammonium compounds and their degradation via dual pathways. Appl Environ Microbiol 73(6):1797-1802

Volkering F, Breure AM, Andel JGv, Rulkens WH (1995) Influence of nonionic surfactants on bioavailability and biodegradation of polycyclic aromatic hydrocarbons. Appl Environ Microbiol 61(5):1699-1705

Weber FJ, deBont JAM (1996) Adaptation mechanisms of microorganisms to the toxic effects of organic solvents on membranes. Biochim Biophys Acta 1286:225-245

Zwieten LV, Kennedy IR (1995) Rapid degradation of atrazine by Rhodococcus sp. NI86/21 and by an atrazine-perfused soil. J Agric Food Chem 43(5):1377-1382 